\title{
Increased perception of mosquito problems during a stormwater restoration project
}

\author{
Rosmarie Kelly ${ }^{1}$ \\ ${ }^{1}$ Public Health Entomologist, Environmental Health Section, Georgia Department of Public Health, Atlanta, GA
}

\section{EXECUTIVE SUMMARY}

In 2008, a plan for improvement of the McDaniel Branch Watershed was prepared for the city of Atlanta, Department of Watershed Management. This included the construction of ponds in a kudzu-covered area at Bowen Circle.

There is a perception that wetlands create mosquito problems. In point of fact, most of the vector and nuisance species in Atlanta are either container breeders or floodwater species, and do not breed in ponds. Because there is an average of 5 cases of West Nile virus (WNV) reported in Fulton County per year, most of these near Combined Sewer Overflow streams, county residents are aware of the connection between mosquitoes and WNV. As the McDaniel Branch Watershed Improvement Plan progressed, neighborhood residents became convinced that the changes being implemented in the area were increasing mosquito problems and increasing their risk of WNV infections.

In Oct 2013, the Environmental Health Section of the Georgia Department of Public Health was contacted by the City of Atlanta Department of Watershed Management concerning control of mosquitoes in the ponds being created at the Bowen Circle site. It was determined that mosquito surveillance should be implemented in the area to determine if the changes to the watershed area were creating a mosquito problem. At the end of the 2014 mosquito surveillance season, it was established that there was little association between the watershed improvement project, the reported mosquito exposure, and measures of mosquito production within this neighborhood.

\section{INTRODUCTION}

Wet ponds are constructed basins that have a permanent pool of water throughout the year (or at least throughout the wet season). Stormwater wetlands (constructed wetlands) are similar to wet ponds but incorporate wetland plants in a shallow pool (http://www.stormwatercenter.net/Assorted\%20Fact\%20She ets/Tool6_Stormwater_Practices/Wetland/Wetland.htm). As stormwater runoff flows through wetlands, pollutant removal is achieved by settling and biological uptake. Wetlands are among the most effective stormwater practices in terms of pollutant removal, and also offer aesthetic value (http://water.epa.gov/type/wetlands/restore/upload/construct ed-wetlands-handbook.pdf ). Stormwater wetlands, which are designed specifically for the purpose of treating stormwater runoff, typically have less biodiversity than natural wetlands in terms of plant and animal life.

Some limitations of stormwater wetlands include the fact that wetlands consume a relatively large amount of space, making them an impractical option on many sites where surface land area is constrained or land prices are high. Further, wetlands require careful design and planning to ensure that wetland plants survive and flourish. Stormwater wetlands may also release nutrients during the non-growing season, leading to increased eutrophication in associated streams

(http://www.edc.uri.edu/nrs/classes/nrs555/assets/readings 2011/SWS-MosquitoWhitePaperFinal.pdf).
Although design features can minimize the potential of wetlands to become breeding areas for mosquitoes, there can be public perception that wetlands are a mosquito $\begin{array}{lll}\text { source } \quad \text { (McLean, } & \text { J. }\end{array}$ http://www.epa.gov/npdes/pubs/sw_wnv.pdf).

Mosquitoes are aquatic insects in the Order Diptera, Family Culicidae. There are more than 3,500 species of mosquitoes worldwide, with about 60 species found in Georgia. Of these, only about 12 are vectors of disease or constitute a nuisance. There are two basic types of mosquitoes, species that lay their eggs in permanent bodies of water and floodwater species.

Mosquitoes have 4 life stages: egg, larva, pupa, and adult. Eggs, larvae, and pupae all require standing water to complete their life cycle. Adults feed on nectar; females need blood to develop eggs. Many species of mosquitoes lay their eggs in vegetated areas containing shallow, slowmoving water. These are characteristics of wetlands. Mosquito breeding can be minimized through site design and management considerations that include provision of mosquito predators such as fish and several types of aquatic insects.

\section{PURPOSE}

The City identified the McDaniel Branch Watershed Improvement Plan (WIP) as a pilot study to develop a community-based approach that can be applied to other WIPs

(http://www.atlantawatershed.org/default/?linkServID=1989 


\section{B-C953-4657-}

BAEAF8FF4681E0D2\&showMeta=2\&ext=.pdf ). Designed to mitigate the impacts of stormwater runoff in Atlanta's intown neighborhoods, the constructed wetlands central to this project mimic natural systems for managing stormwater (Figure 1).

This site was once a part of a Combined Sewer Overflow (CSO) stream area and had become covered with kudzu (Figure 2). These changes occurred in the aftermath of improvements to the local Combined Sewer System. The sanitary and stormwater systems have been split, and the number of overflow events has been reduced. Connected ponds have been added at the site to hold and gradually release water back into the stream. The concern was that the design, which will protect the stream and surrounding area from erosion and silting, might increase the mosquito burden in the area.

\section{Figure 1: McDaniel Branch Watershed WIP}

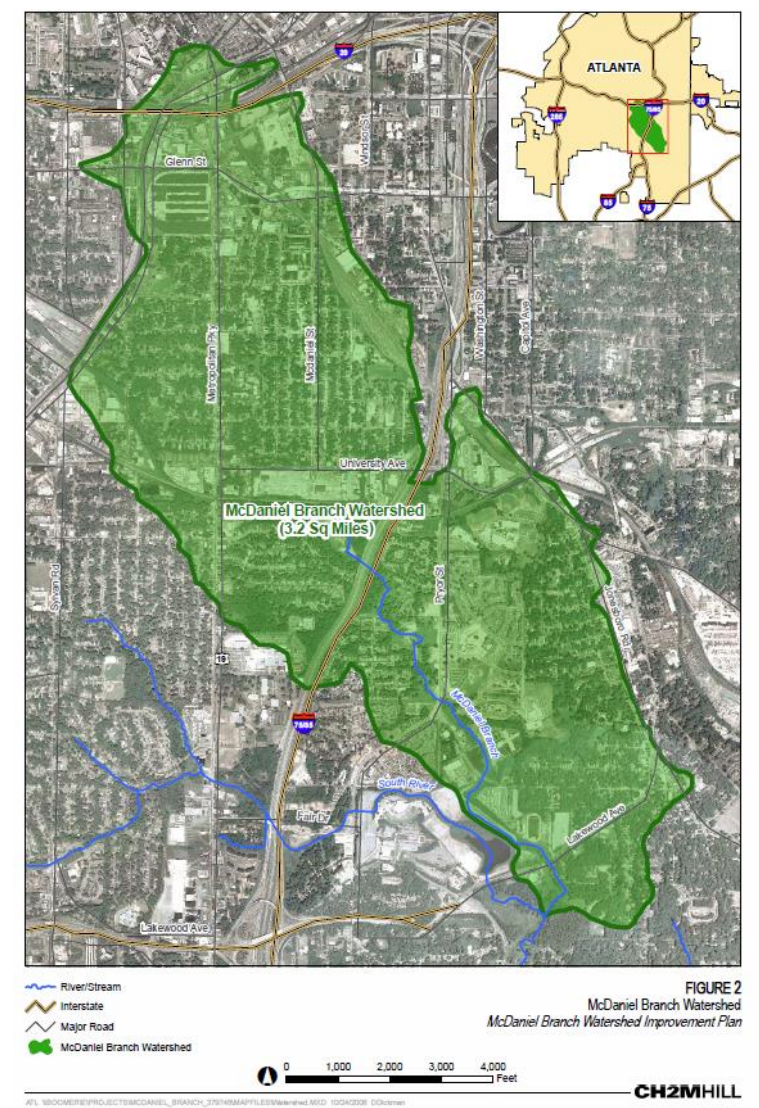

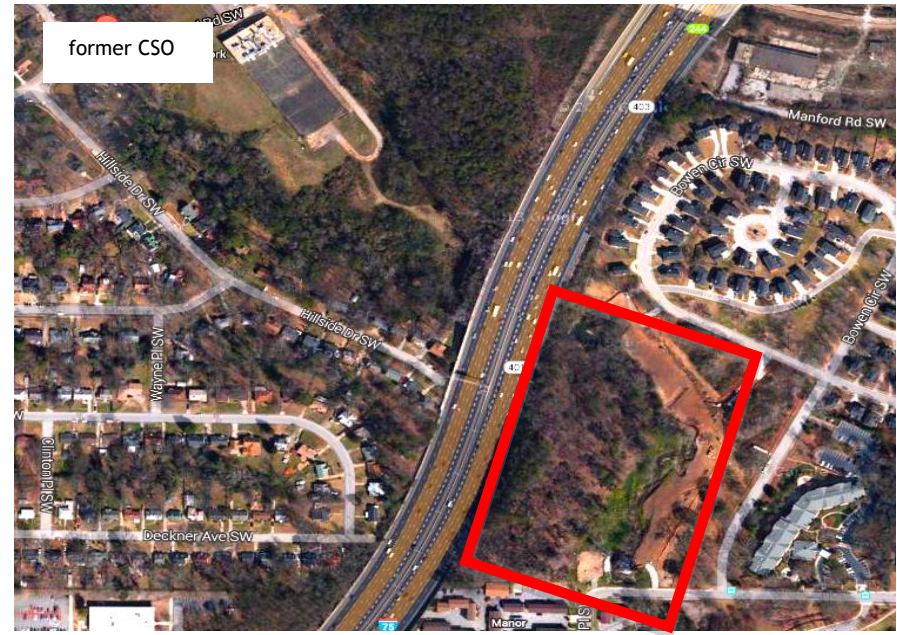

Figure 2: Area around WIP

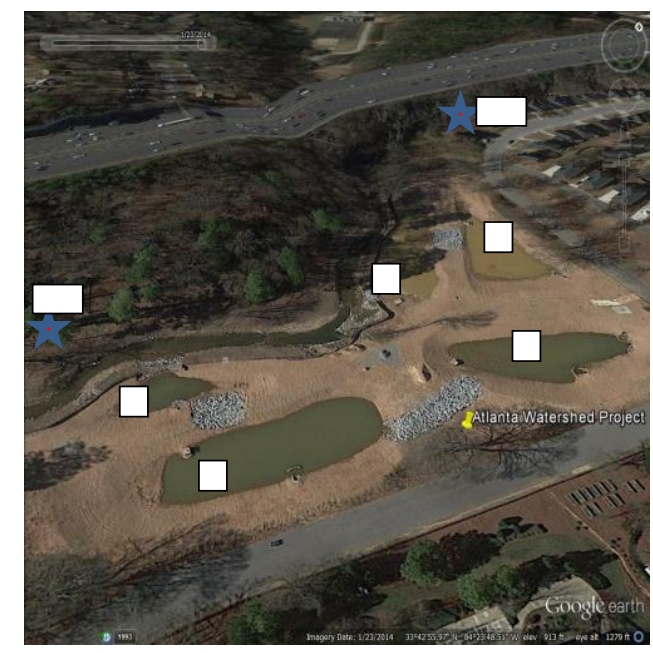

Figure 3: Trap Locations

\section{METHODS}

To determine the effect that the remediation of the site would have on mosquito populations in the area, it was proposed that mosquito surveillance be accomplished at least once a month at the site, starting in May2014. CDC light traps (http://www-rci.rutgers.edu/ insects/cdctrap.htm)

baited with dry ice, which collect mosquitoes looking for a blood meal, were placed in two locations at the ends of the site (Figure 3) once a month and left overnight. Traps were collected and taken to the laboratory where mosquitoes were identified. Trapping continued through September, when cooler nighttime temperatures caused a drop in mosquito populations. 
Area ponds were also checked once a month using a mosquito larval dipper (http://wwwrci.rutgers.edu/ insects/larvsurv.htm). Dips were taken at 10 random sites in each pond to check for mosquito larvae.

Finally, landing counts (http://wwwrci.rutgers.edu/ insects/landing.htm) were made to determine biting pressure. During landing counts, the numbers of mosquitoes that land over a designated period of time are recorded. Counts can be made over either a 1- or 5min period, but the interval can be shortened to protect observers if mosquito numbers are high.

\section{RESULTS}

Overall, the numbers of mosquitoes were low (Table 1). The only mosquito found in abundance was Aedes albopictus, the Asian tiger mosquito. Most of these were trapped from the wooded area below the highway close to the subdivision. As a container breeder, it lays eggs in any container that will hold a small amount of water for a week or so, including magnolia leaves, corrugated pipes, flat roofs, and water barrels (even if covered). While there were several species of mosquitoes trapped that could have come from the pond, no mosquito larvae were found during larval surveillance. This is probably due to the fact that the ponds contain fish that consume mosquito larvae.

Table 1: Mosquito Species Collected at the Watershed Improvement Site

\begin{tabular}{|l|c|c|c|c|c||c|c|}
\hline \multicolumn{1}{|c|}{ species } & May & June & July & Aug & Sept & Grand Total & per trap night \\
\hline Ae. albopictus & 20 & 18 & 27 & 18 & 7 & 90 & 9 \\
\hline Ae. vexans & 21 & 31 & 8 & 13 & 3 & 76 & 7.6 \\
\hline An. crucians & & & & & 1 & 1 & 0.1 \\
\hline An. punctipennis & 6 & 10 & & 1 & 1 & 18 & 1.8 \\
\hline An. quadrimaculatus & & & & 1 & & 1 & 0.1 \\
\hline Cx. erraticus & & & 3 & 11 & 3 & 17 & 1.7 \\
\hline Cx. quinquefasciatus & 3 & 5 & 5 & & 1 & 14 & 1.4 \\
\hline Cx. restuans & 3 & & & & & 3 & 0.3 \\
\hline Cx. salinarius & 4 & & & & & 4 & 0.4 \\
\hline Oc. triseriatus & 1 & & & 2 & & 3 & 0.3 \\
\hline Ps. columbiae & & 1 & 1 & & 1 & 3 & 0.3 \\
\hline Ps. horrida & & & & 1 & & 1 & 0.1 \\
\hline Ps. howardii & & & & 1 & & 1 & 0.1 \\
\hline Ur. sapphirina & & & 1 & & & 1 & 0.1 \\
\hline \multicolumn{1}{|c|}{ Grand Total } & 58 & 65 & 45 & 48 & 17 & 233 & \\
\hline
\end{tabular}

\section{DISCUSSION}

Within this neighborhood, we found little association between reported mosquito exposure and our measures of mosquito production. However, area residents still chose to believe that the mosquito problem was caused by the ongoing watershed improvement. In order to continue monitoring the situation, the plan for 2015 is to hire a company to control mosquitos at the site, with a goal of having less than one larva on average per dip in each pond, with a surveillance level of 10 dips at random locations in each pond every two weeks. Additionally, the entire area should be monitored at least once a month for potential breeding sites not associated with the ponds. Further, adult mosquito populations should be monitored every 2 weeks with the goal of determining the species and number of mosquitoes being found in the area. Plans already in place for mosquito control, including source reduction, larviciding, and biological control, and for interacting with and educating area residents will be continued.

\section{Implications for Public Health}

This study presents several implications for the field of public health. It will help in evaluating the impact of modifications to watershed areas on mosquito populations in the McDaniel Branch Watershed area and in understanding how data relating to mosquitos are collected and how mosquitoes can be controlled. It will also increase the knowledge of public health practitioners in regard to mobilizing community partnerships. 


\section{References}

McLean, J. 2000. Mosquitos in Constructed Wetlands - A Management Bugaboo?, Article 100 in The Practice of Watershed Protection. Center for Watershed Protection. Ellicott City, MD. http://www.stormwatercenter.net/Practice/100Mosquitos\%20in\%20Constructed\%20Wetlands.pdf

Stormwater Management Fact Sheet: Stormwater Wetland http://www.stormwatercenter.net/Assorted\%20Fact\%20Sheets/T ool6 Stormwater Practices/Wetland/Wetland.htm

Current Practices in Wetland Management for Mosquito Control http://www.edc.uri.edu/nrs/classes/nrs555/assets/readings_2011/ SWS-MosquitoWhitePaperFinal.pdf

EPA Handbook of Constructed Wetlands http://water.epa.gov/type/wetlands/restore/upload/constructedwetlands-handbook.pdf
EPA Stormwater Structures and Mosquitoes http://www.epa.gov/npdes/pubs/sw_wnv.pdf

Atlanta Watershed Project Report http://www.atlantawatershed.org/default/?linkServID=1989764 B-C953-4657-BAEAF8FF4681E0D2\&showMeta=2\&ext=.pdf The CDC Trap as a Special Monitoring Tool http://www-rci.rutgers.edu/ insects/cdctrap.htm Guidelines for Larval Surveillance http://www-rci.rutgers.edu/ insects/larvsurv.htm Landing Rates and Bite Counts for Nuisance Evaluation http://www-rci.rutgers.edu/ insects/landing.htm 